\title{
Seletividade de herbicidas com atividade residual em cebola cultivada em semeadura direta
}

\section{Selectivity of herbicides with residual activity in onion grown in direct seedling}

\author{
Dieisson Olescowicza, Diogo L. Fruetb* ${ }^{*}$, Gustavo Cunhaa, Leonardo Luiza, Naiara Guerrac, Antonio M. de Oliveira Neto ${ }^{b}$ \\ ${ }^{a}$ Departamento de agronomia, Instituto Federal Catarinense, Rio do Sul, SC, Brasil, ${ }^{b}$ Departamento de agronomia, Universidade do Estado de \\ Santa Catarina, Lages, SC, Brasil, 'Departamento de Agronomia, Universidade Federal de Santa Catarina, Curitibanos, SC, Brasil
}

Resumo: Introdução: O sistema de semeadura direta pode ser uma alternativa para reduzir custos e mão-de-obra na produção de cebola, pois não requer as etapas de produção e transplante das mudas. No entanto, esse sistema resulta em uma interferência precoce das plantas daninhas, alongando o período crítico de prevenção à interferência.

Objetivo: Avaliar a seletividade de aplicações de herbicidas com atividade residual em cebola.

Métodologia: três estudos foram realizados em casa de vegetação. $\mathrm{O}$ primeiro conduzido em esquema fatorial $5 \times 4$, avaliando os herbicidas flumioxazin, oxadiazon, oxyfluorfen, pendimethalin e diuron em $0,30,60 \mathrm{e}$ $100 \%$ da dose de referência do herbicida. No segundo estudo, dois herbicidas, pendimethalin e diuron, foram aplicados em três estádios de desenvolvimento da cebola: pré-emergência total com aplicação após a semeadura, aplicação no final da germinação, 15 dias após a semeadura e aplicação no estabelecimento da cebola, aos 21 dias após a semeadura. Um terceiro experimento foi realizado comparando a seletividade do Smetolachlor à cebola.

Resultados: A aplicação de herbicida na fase de estabelecimento da cebola foi mais seletiva. Os herbicidas oxadiazon, oxyfluorfen e flumioxazin não apresentaram uso potencial na aplicação inicial devido à alta fitotoxicidade. Conclusão: A aplicação de pendimethalin e S-metolachlor no final do estabelecimento da cebola foi seletiva e mais uma alternativa ao controle de plantas daninhas no sistema de produção de cebola por semeadura direta.

Palavras-chave: allium cepa, controle de plantas daninhas, técnicas de aplicação.

Journal Information:

ISSN: $2763-8332$

Website: https://www.weedcontroljournal.org/

Jornal da Sociedade Brasileira da Ciência das Plantas

Daninhas

Como citar: Olescowicz D, Fruet DL, Cunha G, Luiz L, Guerra N, Oliveira Neto AM. Seletividade de herbicidas com atividade residual em cebola cultivada em semeadura direta. Weed Control J. 2021;20:e202100739.

https://doi.org/10.7824/wcj.2021;20:00739

Aprovado por:

Editor-Chefe: Daniel Valadão Silva

Editor Associado: Theodoro Schneider

Conflitos de interesse: Os autores declaram não haver conflito de interesses em relação à publicação deste manuscrito.

Recebido: Novembro 09, 2020

Aprovado: Abril 20, 2021

* Corresponding author

<diogofruet17@gmail.com>

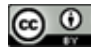

Este é um artigo de acesso aberto distribuído sob os termos da Licença de Atribuição Creative Commons, que permite o uso irrestrito, distribuição e reprodução em qualquer meio, desde que o autor original e a fonte sejam creditados.

Copyright: 2021
Abstract: Background: The direct seeding system can be an alternative to reduce costs and labor in onion production, as it does not require the steps of production and transplantation of seedlings. However, this system results in early weed interference, lengthening the critical period of interference prevention.

Objective: To evaluate the selectivity of herbicide applications with residual activity on onions.

Methods: Three studies were carried out in a greenhouse. The first was carried out in a $5 \times 4$ factorial scheme, evaluating the herbicides flumioxazin, oxadiazon, oxyfluorfen, pendimethalin and diuron at $0,30,60$ and $100 \%$ of the herbicide reference dose. In the second study, two herbicides, pendimethalin and diuron, were applied at three stages of onion development: total pre-emergence with application after sowing, application at the end of germination, 15 days after sowing and application in the onion establishment, at 21 days after sowing. A third experiment was carried out comparing the selectivity of S-metolachlor to onion.

Results: The herbicide application in the onion establishment phase was more selective. The herbicides oxadiazon, oxyfluorfen and flumioxazin showed no potential use in the initial application due to their high phytotoxicity.

Conclusion: The application of pendimethalin and S-metolachlor at the end of onion establishment was selective and another alternative to weed control in the no-tillage onion production system.

Keywords: allium cepa, weed control, application techniques.

\section{Introdução}

A produção de hortaliças no Brasil ocupa área de 237.511 ha, sendo que a cebola é cultivada em 47.490 ha (Hortifruti Brasil, 2019), correspondendo cerca de $20 \%$ de toda a área cultivada com hortaliças. A região Sul do Brasil é a maior produtora de cebola, com 803.703 t(Ibge, 2018). Responsável por $41 \%$ da área plantada brasileira (Hortifruti Brasil, 2019), o estado de Santa Catarina se destaca como maior produtor nacional, com área de 18.960 ha, produtividade média de $25.586 \mathrm{~kg} \mathrm{ha}^{-1}$ e produção total de 485.122 t, na safra 2018/19 (Epagri/Cepa, 2019).

Tradicionalmente cultivada a partir de mudas, a cultura da cebola vem enfrentando problemas na produção, principalmente no que se refere a mão-deobra. Assim sendo, nos últimos anos tem aumentado o interesse de produtores pelo sistema de semeadura direta, devido às vantagens econômicas e menor uso de mãoobra que este sistema de cultivo proporciona (Factor et al. 2011).

A baixa capacidade de competição da cebola com as plantas daninhas ocorre principalmente nos estádios iniciais de desenvolvimento da cultura, principalmente devido ao seu crescimento inicial muito lento. Longos períodos de convivência entre a cebola e plantas daninhas podem reduzir totalmente a produção de bulbos (Souza et al., 2016). Existe uma grande variação nos resultados de estudos de interferência de plantas daninhas (Souza et al. 2016); para a cebola transplantada, o período crítico de prevenção a interferência vai de 7 a 60 dias após o transplante. Outro trabalho desenvolvido por Souza et al. (2016) apontou que o período crítico de interferência foi de 23 a 73 dias após o transplante. Entretanto, sabe-se que em sistema de semeadura direta a interferência de plantas daninhas é mais prejudicial que em cebola transplantada (Jat et al, 2018). Nesse sistema de produção, o controle químico é a principal medida para evitar a interferência das plantas daninhas (Priya et al., 2017). 
No Brasil, embora existam herbicidas registrados para a cultura da cebola (11 ingredientes ativos), grande parte deles (85\%) apresentam recomendação para o sistema de transplante de mudas ou de bulbilhos (Agrofit, 2019). As plantas de cebola provenientes de semeadura direta têm se mostrado mais sensíveis aos herbicidas, principalmente aos latifolicidas, apresentando grande redução na produção quando estes são utilizados nas doses indicadas para o sistema de mudas transplantadas (Ferreira et al., 2000). Os herbicidas oxyfluorfen e ioxynil em doses reduzidas, têm apresentado resultados promissores (Ferreira et al., 2000), porém insuficientes para manter a cultura livre da interferência das plantas daninhas, principalmente no início do período crítico.

Apesar da importância do controle químico, ainda são escassos na literatura trabalhos relacionados a seletividade de herbicidas em cebola cultivada em sistema de semeadura direta. Desta forma, este trabalho teve como objetivo avaliar a seletividade da aplicação de herbicidas com atividade residual no solo, em cebola cultivada no sistema de semeadura direta.

\section{Material e Métodos}

\section{Local e delineamento experimental}

Os três experimentos foram conduzidos, todos em casa de vegetação com irrigação diária, localizada no Campus Sede do Instituto Federal Catarinense (IFC) no município de Rio do Sul, SC (Latitude: $27^{\circ} 11^{\prime} \mathrm{O} 7^{\prime}$ S e Longitude: 49³9'39" $\mathrm{O}$ e altitude de 650 metros). Todos os experimentos foram conduzidos em delineamento inteiramente casualizado com quatro repetições.

As unidades experimentais consistiram em vasos plásticos com capacidade de $8 \mathrm{dm}^{3}$, preenchidos com solo peneirado oriundo da camada de 0 a $5 \mathrm{~cm}$ de uma área agrícola. A cultivar utilizada foi a Bola Precoce.

\section{Dose resposta de herbicidas com atividade residual}

Os tratamentos foram organizados em esquema fatorial $5 \times 4$, totalizando 20 tratamentos. O primeiro fator estudado foram os cinco herbicidas (flumioxazin, oxadiazon, oyfluorfen, pendimethalin e diuron) e o segundo fator avaliado consistiu em quatro doses $(0,30,60$ e $100 \%$ da dose de bula). A dose de referência (100\%) foi de $60 \mathrm{~g} \mathrm{ha}^{-1}$ de ingrediente ativo (i.a.), $1.050 \mathrm{~g} \mathrm{ha}^{-1}$ de i.a., $288 \mathrm{~g} \mathrm{ha}^{-1}$ de i.a., $1.680 \mathrm{~g} \mathrm{ha}^{-1}$ de i.a e $600 \mathrm{~g} \mathrm{ha}^{-1}$ de i.a., para flumioxazin, oxadiazon, oxyfluorfen, pendimethalin e diuron, respectivamente. $\mathrm{Em}$ cada unidade experimental foram semeadas quatro sementes. A aplicação foi realizada após o final da emergência da cebola, 15 dias após semeadura (DAS).

\section{Época de aplicação de pendimethalin e diuron}

Neste experimento foram selecionados os herbicidas que apresentaram maior seletividade no primeiro experimento e testados em diferentes estádios de aplicação. Os tratamentos foram organizados em esquema fatorial $3 \times 3$, totalizando nove tratamentos. Os tratamentos foram: testemunha sem herbicida, diuron (250 g i.a. ha $\left.{ }^{-1}\right)$ e pendimethalin (600 g i.a. ha ${ }^{-1}$ ) combinados com três estádios de desenvolvimento da cebola na aplicação, sendo: préemergência total com aplicação após a semeadura, final da emergência 15 DAS e estabelecimento da cebola aos 21 DAS (chicote). Em cada unidade experimental foram semeadas 6 sementes.

\section{Seletividade de S-metolachlor}

Neste experimento realizou-se a avaliação da seletividade do herbicida S-metolachlor, utilizando pendimethalin como tratamento referência. Nesse experimento avaliou-se doses de S-metolachlor (0, 240, 480, $720,960,1200$ e $1440 \mathrm{~g}$ i.a. ha-1) e pendimethalin (600 e $1.200 \mathrm{~g}$ i.a. ha-1), totalizando 10 tratamentos. Os tratamentos foram aplicados na fase de final da emergência da cebola, 12 DAS. Em cada unidade experimental foram semeadas seis sementes.

\section{Aplicação dos tratamentos}

Os tratamentos foram aplicados com o auxílio de um pulverizador costal pressurizado a $\mathrm{CO}_{2}$, munido de barra com quatro pontas de jato plano modelo TT 110015, pressão de trabalho de $207 \mathrm{kPa}$, velocidade de deslocamento de $3,6 \mathrm{~km} \mathrm{~h}^{-1}$, espaçamento entre bicos de $0,50 \mathrm{~m}$, altura da barra em relação ao alvo de $0,50 \mathrm{~m}$, com volume de aplicação equivalente a $150 \mathrm{~L} \mathrm{ha}^{-1}$.

\section{Variáveis avaliadas}

No primeiro experimento foi avaliado a fitointoxicação visual nas plantas aos 15 dias após aplicação (DAA) e a altura de plantas e massa seca da parte aérea da cebola aos 60 DAA. Dentro do segundo experimento foi avaliado a fitointoxicação visual, altura de plantas, número de plantas e massa seca da parte aérea aos 30 DAA. E no terceiro experimento as variáveis avaliadas foram: a fitointoxicação visual, altura de plantas e massa seca da parte aérea aos 30 DAA.

\section{Análise estatística}

Os dados foram submetidos a análise de variância pelo teste F. No primeiro experimento realizou-se análise de regressão polinomial. No segundo experimento comparou-se a médias pelo teste de Tukey. No terceiro experimento, as doses de S-metolachlor foram submetidas à análise de regressão não-linear e a comparação entre os herbicidas foi realizada pelo teste de Tukey. Em todas as análises utilizouse $5 \%$ de probabilidade $(\mathrm{p}<0,05)$.

\section{Resultados e Discussão}

Dose resposta de herbicidas com atividade residual

A aplicação inicial de oxadiazon e oxyfluorfen causou a morte das plântulas de cebola já a partir da menor dose (dados não apresentados), ou seja, esses tratamentos não 
foram seletivos nessa época de aplicação. Esses resultados podem estar associados a elevada sensibilidade da cebola aos herbicidas na fase de estabelecimento, pois efeitos distintos foram descritos por Hermmann et al. (2017) com a aplicação de oxyfluorfen em pós-emergência no estádio de duas a quatro folhas, causando apenas 20\% de fitointoxicação. A aplicação em pré-semeadura, aplicação no dia da semeadura e antes da irrigação, com oxadiazon e oxyfluorfem também foi seletiva para a cebola (Ghosheh, 2004).
Os herbicidas flumioxazin, diuron e pendimethalin tiveram resposta linear positiva para fitointoxicação com o aumento das doses (Figura 1A). O flumioxazin ocasionou a maior fitointoxicação, não sendo seletivo para cebola quando aplicado aos 15 DAS mesmo na menor dose. A aplicação de flumioxazin (72 $\mathrm{g} \mathrm{ha}^{-1}$ ) em pós-emergência, em cebola com duas folhas, apresentou seletividade, ocasionando $33 \%$ de fitointoxicação (Hermann et al., 2017).

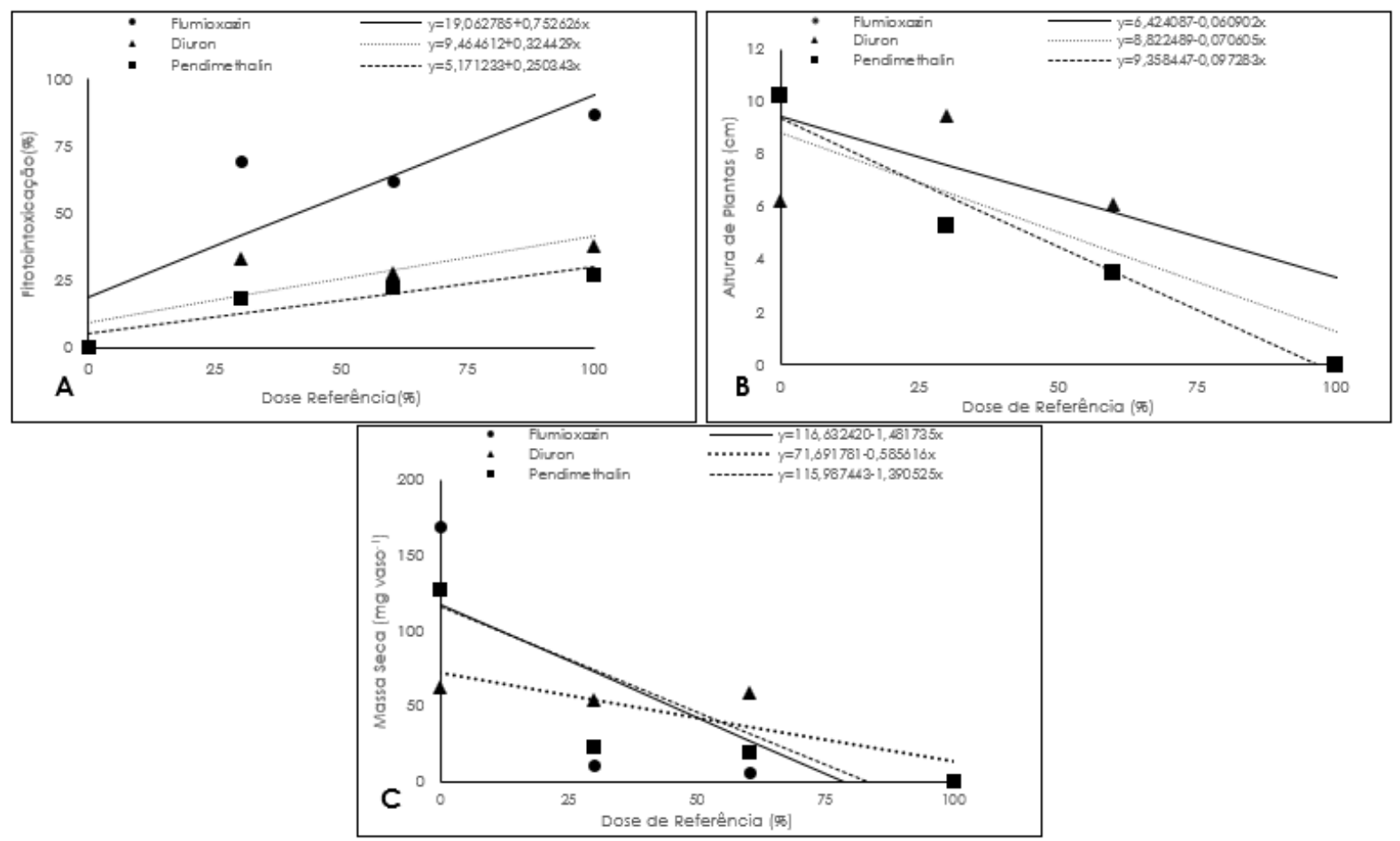

Figura 1. Avaliações de fitointoxicação (\%) (A), altura da planta $(\mathrm{cm})(\mathrm{B})$ e peso da parte aérea $(\mathrm{mg}$ vaso-1) $(\mathrm{C})$ de cebola submetida à aplicação de flumioxazina, diuron e pendimethalin na fase final de emergência (15 DAS). Rio do Sul, SC, 2017.

A falta de seletividade durante o processo de emergência pode estar associada a ausência de acúmulo de cera no limbo foliar. A maior quantidade de cera nas folhas é possivelmente a causa da maior tolerância em estádios mais avançados de desenvolvimento. Além disso, em estádios mais avançados da cebola verifica-se a formação de bainhas imbricadas, o que confere uma maior proteção em relação ao contato do herbicida (Oliveira et al. 2018). Durigan et al., (2005) avaliaram a aplicação de herbicidas em pré-emergência no sistema de produção de cebola transplantada e concluíram que flumioxazin foi seletivo para a cultura nas doses de 0,080 a $0,240 \mathrm{~g} \mathrm{ha}^{-1}$. O oxadiazon a $0,75 \mathrm{~kg} \mathrm{ha}^{-1}$ provocou sintomas iniciais de fitointoxicação, mas as plantas se recuperaram totalmente. A mistura de oxadiazon + linuron $(0,50+$ $\left.0,90 \mathrm{~kg} \mathrm{ha} \mathrm{h}^{-1}\right)$ e linuron isolado $\left(1,35 \mathrm{~kg} \mathrm{ha} \mathrm{ha}^{-1}\right)$ promoveram fitointoxicação de moderada a média (20 a 40\%).

$\mathrm{O}$ aumento de dose comprometeu a seletividade dos herbicidas em todas as variáveis avaliadas (Figura 1A, B e C), indicando que apenas o diuron e pendimethalin com $25 \%$ da dose de referência apresentaram potencial de seletividade para a cebola. A seletividade de diuron e pendimethalin para a cebola transplantada já foi relatada (Ferreira et al., 1999,
Grey et al., 2008). Ferreira et al. (1999) avaliaram a eficiência e seletividade de fluazifop-p-butil, oxyfluorfen e ioxynil para a cebola, com a aplicação feita no estabelecimento, 19 DAS, e concluíram que todos os tratamentos foram seletivos, não apresentando nenhum sintoma de fitotoxicidade aos 20 DAA.

Estes resultados demonstram que a seletividade de herbicidas para cebola de semeadura direta é um gargalo na fase inicial de desenvolvimento. Os herbicidas pendimethalin e diuron apresentaram potencial de uso somente quando aplicados em subdoses.

Época de aplicação de pendimethalin e diuron

$\mathrm{O}$ herbicida diuron promoveu sintomas de fitointoxicação em todos os estádios de aplicação, com maior intensidade na aplicação no final da emergência (Tabela 1). Para pendimethalin, a maior fitointoxicação ocorreu nas aplicações de pré-total e final da emergência. A aplicação de pendimethalin no estabelecimento da cebola não diferiu da testemunha, indicando a maior seletividade neste estádio (Tabela 1). 
Tabela 1. Fitointoxicação (\%), altura da planta $(\mathrm{cm})$, número de plantas $(\mathrm{n})$, peso da parte aérea $(\mathrm{mg}$ vaso-1) e coeficiente de variação $(\mathrm{CV} \%)$, dependendo da aplicação de diuron e pendimethalin, em três estágios de cebola cultura, avaliação aos 30 DAA. Rio do Sul, SC, 2017.

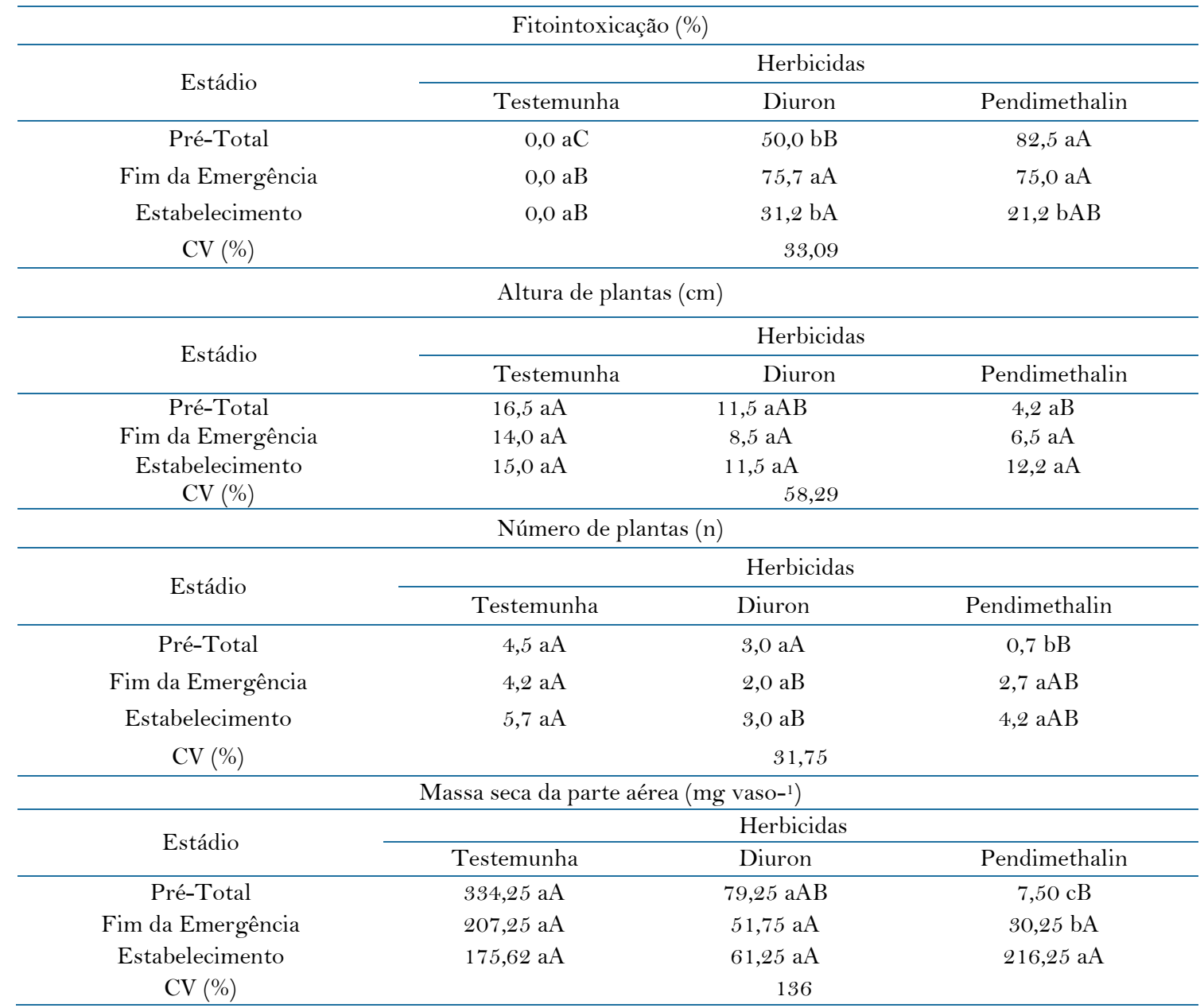

Medias seguidas de mesma letra minúscula na coluna e maiúscula na linha não diferem pelo teste de Tukey $(\mathrm{p}>0,05)$.

Quanto à possível fitotoxicidade causada pelos herbicidas, segundo estudos de Souza et al. (2015), realizou experimento com aplicação de herbicidas 30 dias após o transplante, com ioxynil-octanoato $\left(0,250 \mathrm{~kg} \mathrm{ha}^{-1}\right)$, flumioxazin $\left(0,07 \mathrm{~kg} \mathrm{ha}^{-1}\right)$, oxadiazon $\left(1,0 \mathrm{~kg} \mathrm{ha}^{-1}\right)$ e bentazon $\left(0,78 \mathrm{~kg} \mathrm{ha}^{-1}\right)$, somente oxadiazon causou danos a parte aérea da cultura, com sintoma de manchas cloróticas e pequenas necroses.

A altura de plantas não foi afetada pela aplicação de diuron em nenhuma das épocas. Da mesma forma, as aplicações de pendimethalin no final da emergência e no estabelecimento não prejudicaram o crescimento da cebola (Tabela 1). Estes resultados corroboram com a pesquisa de Norsworthy et al. (2007), que relataram baixa fitointoxicação com a aplicação inicial de pendimethalin e S-metalachlor em cebolinha verde.

O número de plantas não foi afetado pelo diuron quando aplicado em pré-total, mesmo com a elevada fitointoxicação. Entretanto quando aplicado no final da emergência e estabelecimento, houve redução significativa no número de plantas em relação a testemunha (Tabela 1). O pendimethalin afetou significativamente o número de plantas apenas quando aplicado em pré-total (Tabela 1).
Com relação a massa seca, diuron apresentou menor redução de massa seca, quando aplicado no estádio de prétotal (Tabela 1). A baixa seletividade de diuron pode estar relacionada a facilidade de absorção do herbicida neste estádio, para Silva et al. (2013) a absorção de herbicidas do grupo químico inibidores do fotossistema II é favorecida quando as plantas são mais jovens, assim o herbicida pode, mesmo em baixas concentrações, atingir o alvo com elevada eficiência.

Pendimethalin ocasionou a maior redução de massa seca no estádio de pré-total e fim da emergência, entretanto quando aplicado no estabelecimento não afetou a massa seca da parte aérea. Esse resultado comprova a importância do estádio de desenvolvimento para a seletividade deste herbicida. A seletividade de pendimethalin na aplicação no estabelecimento pode estar associada a absorção deste herbicida em tecidos muitos jovens. Segundo Silva e Monquero (2013), pendimethalin é absorvido por compostos orgânicos, apresenta elevado valor de kow (coeficiente de lipofilicidade), assim se liga facilmente a compostos apolares. Sabe-se que no período de emergência a parte aérea da plântula é desprovida de cera, sendo um tecido muito permeável. Com o avanço do estádio, após o estabelecimento, 
a planta inicia a deposição de cera reduzindo a absorção do herbicida e não afetando de forma significativa o desenvolvimento da planta. Destaca-se que pendimethalin é um herbicida de elevada lipofilicidade e com ação de contato em superfícies cerosas.

\section{Seletividade de S-metolachlor}

A seletividade de S-metolachlor foi reduzida com aumento da dose, pode-se observar que a dose máxima promoveu fitointoxicação próxima a $74 \%$ (Figura 2). A altura de plantas e a massa seca da parte aérea sofreram decréscimos com o aumento da dose de S-metolachlor (Figura 2). De modo geral, doses menores que $480 \mathrm{~g} \mathrm{ha}^{-1}$ de S-metolachlor tiveram baixo impacto negativo sobre o crescimento inicial da cebola.

Pesquisas anteriores demonstraram que a seletividade do S-metolachlor para a cebola transplantada é afetada pela dose, sendo que a aplicação de $1.920 \mathrm{~g}$ ha $^{-1}$ em préemergência ocasionou $25 \%$ de redução na produtividade de bulbos da cebola (Hussain et al., 2008).
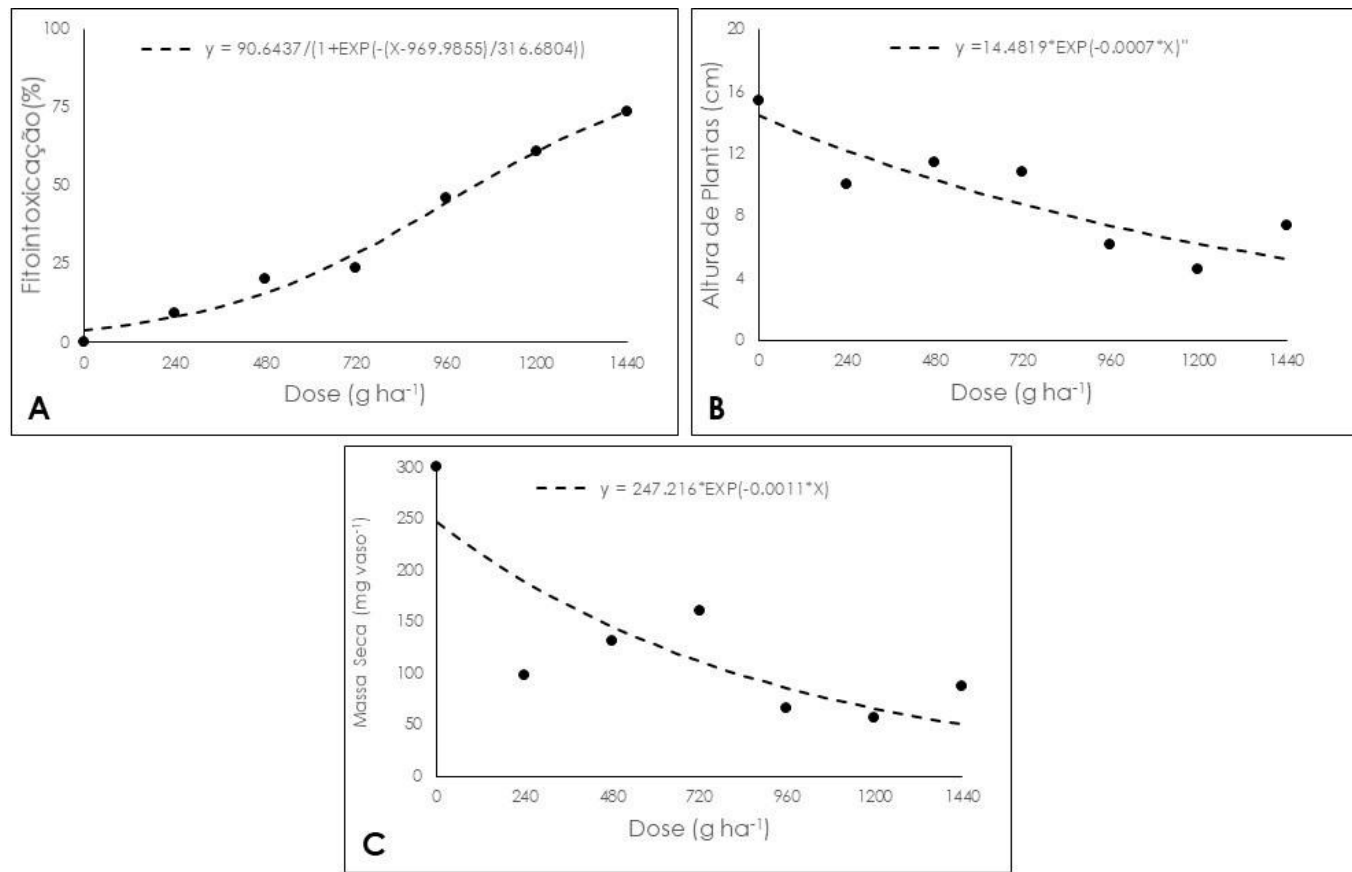

Figura 2. Fitointoxicação (\%) (A), altura da planta $(\mathrm{cm})(\mathrm{B})$ e peso seco da parte aérea $\left(\mathrm{mg}\right.$ vaso-1 $\left.^{-1}\right)$ (C) da cebola aos 30 dias após a aplicação, dependendo da dose de S-metolaclor aplicada aos 12 dias após a semeadura. Rio do Sul, SC, 2017.

A fitointoxicação promovida por S-metolachlor nas doses de $480 \mathrm{~g} \mathrm{ha}^{-1}$ e $720 \mathrm{~g} \mathrm{ha}^{-1}$ foi semelhante a aplicação de pendimethalin (600 e $\left.1200 \mathrm{~g} \mathrm{ha}^{-1}\right)$. Doses superiores a estas ocasionaram fitointoxicação elevada $(>25 \%)$. S-metolachlor até $720 \mathrm{~g} \mathrm{ha}^{-1}$ e pendimethalin nas duas doses não afetaram a altura de plantas. Para massa seca da parte aérea apenas Smetolachlor na dose de $720 \mathrm{~g} \mathrm{ha}^{-1}$ e pendimethalin a $600 \mathrm{~g} \mathrm{ha}^{-}$ 1 , não diferiram da testemunha (Tabela 2).

Tabela 2. Avaliações de fitointoxicação (FITO em\%), altura da planta (ALT em $\mathrm{cm}$ ) e massa seca da parte aérea $\left(\mathrm{MSPA}_{\mathrm{em} \mathrm{mg} \text { vaso-1}}{ }^{1}\right.$ ), aos 30 DAA. Rio do Sul, SC, 2017.

\begin{tabular}{|c|c|c|c|}
\hline Herbicida & FITO & ALT & MSPA \\
\hline S-metolachlor - $0 \mathrm{~g} \mathrm{ha}^{-1}$ & $\mathrm{O}, \mathrm{Of}$ & $15,4 \mathrm{a}$ & $300,0 \mathrm{a}$ \\
\hline S-metolachlor - $240 \mathrm{~g} \mathrm{ha}^{-1}$ & 9,5 ef & $10,1 \mathrm{abcd}$ & $98,7 \mathrm{~b}$ \\
\hline S-metolachlor - $480 \mathrm{~g} \mathrm{ha}^{-1}$ & 20,5 cde & $11,5 \mathrm{abc}$ & $131,7 \mathrm{~b}$ \\
\hline S-metolachlor - $720 \mathrm{~g} \mathrm{ha}^{-1}$ & $23,7 \mathrm{~cd}$ & $10,9 \mathrm{abcd}$ & $161,5 \mathrm{ab}$ \\
\hline S-metolachlor - $960 \mathrm{~g} \mathrm{ha}^{-1}$ & $46,2 \mathrm{~b}$ & $6,2 \mathrm{~cd}$ & $66,0 \mathrm{~b}$ \\
\hline S-metolachlor - $1200 \mathrm{~g} \mathrm{ha}^{-1}$ & $61,2 \mathrm{a}$ & $4,6 \mathrm{~d}$ & $57,7 \mathrm{~b}$ \\
\hline S-metolachlor - $1440 \mathrm{~g} \mathrm{ha}^{-1}$ & 73,7 a & $7,4 \mathrm{bcd}$ & $88,0 \mathrm{~b}$ \\
\hline Pendimethalin - $600 \mathrm{~g} \mathrm{ha}^{-1}$ & 12,5 def & $13,5 \mathrm{ab}$ & $179,5 \mathrm{ab}$ \\
\hline Pendimethalin - $1200 \mathrm{~g} \mathrm{ha}^{-1}$ & $26,2 \mathrm{c}$ & $11,4 \mathrm{abc}$ & $128,7 \mathrm{~b}$ \\
\hline
\end{tabular}

Medias seguidas de mesma letra não diferem entre si pelo teste de Tukey $(p>0,05)$. 
S-metolachlor e pendimethalin, apresentaram resultados satisfatórios com aplicações realizadas na fase de estabelecimento de cebola em sistema de semeadura direta, apesar dos dados apresentarem bom indicativo disso são necessários estudos a campo, com a verificação de diferentes condições edafoclimáticas e diferentes genótipos de cebola. Através dos resultados obtidos já se tem a informação de qual a melhor época para a aplicação dos herbicidas neste sistema de semeadura, que é na fase do estabelecimento.

\section{Conclusões}

O oxadiazon, oxyfluorfen, flumioxazin e diuron não foram seletivos para a aplicação na cultura da cebola em sistema de semeadura direta, quando aplicados logo após a emergência.

O S-metolachlor na dose de até $720 \mathrm{~g}$ ha $^{-1} \mathrm{e}$ pendimethalin $600 \mathrm{~g} \mathrm{ha}^{-1}$, apresentam seletividade para a cultura quando aplicados na fase de estabelecimento da cebola, assim podem ser alternativas de controle de plantas daninhas para implantação do sistema de semeadura direta de cebola.

O estádio da cebola no momento da aplicação é decisivo para a seletividade de herbicidas.

Referências

Agrofit. Sistemas de agrotóxicos fitossanitários. Disponível em: <http://extranet.agricultura.gov.br/agrofit_cons/ principal_agrofit_cons $>$. Acesso em 10 nov. 2019.

Durigan JC, Silva MR, Pazania AA. Eficácia e seletividade do herbicida flumioxazin aplicado em pré-emergência na cultura transplantada da cebola. Revista Brasileira de Herbicidas, 2005;1(3):11-17. Available from: https://doi.org/10.7824/ rbh.v4i3.33

EPAGRI/CEPA. Números da agropecuária catarinense 2019: Cebola. 2019. https://cepa.epagri.sc.gov.br/index.php/ produtos/acompanhamento-de-safras/. Acesso em: 10 vov. 2019

Factor TL, Lima JRS, Purquerio LFV, Silveira JMC, Calori AH, Guimarães RS, Santello M, Ronchi RSM. Produtividade da cebola em plantio direto em função de doses e parcelamento da adubação potássica. Horticultura Brasileira, 2011;29(3):3966-3974. Available from: http:// www.abhorticultura.com.br/eventosx/trabalhos/ev_5/ A4027_T6494_Comp.pdf

Ferreira LR, Durigan JC, Churata-masca MGC. Eficácia de herbicidas no controle de plantas daninhas na cultura da cebola em semeadura direta. Planta Daninha.1999;17 (1):6372. Available from: https://doi.org/10.1590/So10083581999000100006 .

Ferreira LR, Durigan JC, Churata-masca MGC, Ferreira FA, Silva AA. Seletividade e eficácia da aplicação sequencial de oxyfluorfen e de ioxynil-octanoato, em semeadura direta de cebola. Planta Daninha. 2000;18(1):39-50. Available from: https://doi.org/10.1590/S0100-83582000000100004

Ghosheh HZ, Single herbicide treatments for control of broadleaved weeds in onion (Allium cepa). Crop Protection.2004;23(6):539-542. Available from: https:// doi.org/10.1016/j.cropro.2003.10.010

Grey TL, Macrae A, Culpepper AS. Transplanted onion response to previously applied residual herbicides. Weed Technology. 2008;22(3)477-480. Available from: https:// doi.org/10.1614/WT-08-018.1
Herrmann CM, Goll MA, Phillipo CJ, Zandstra BH. Postemergence weed control in onion with bentazon, flumioxazin, and oxyfluorfen. Weed Technology. 2017;31(2) 279-290. Available from: https://doi.org/10.1017/ wet.2016.16

HORTIFRUTI BRASIL, 2019. Perspectivas HF 2019. https://www.hfbrasil.org.br/br/revista/acessar/completo/ anuario-2018-2019.aspx. acesso em: 10 nov. 2019.

Hussain Z, Marwat KB, Shah SIA, Arifullah SA, Khan NM. Evaluation of different herbicides for weed control in onion. Sharad Journal Agriculture. 2008;24(3):453-456. Available from: https : / / w w w.researchgate.net/ publication/314214212_EVALUATION_OF_DIFFERENT _HERBICIDES_FOR_WEED_CONTROL_IN_ONION

IBGE. Levantamento Sistemático da Produção Agrícola: Cebola. 2018. https://sidra.ibge.gov.br/ tabela/1618\#resultado Acesso em: 05 jan. 2018.

Jat PK, Choudhary K, Klandelwal SK, Integrated weed management studies in onion (Allium cepa) during rabi and krarif season. International Journal of Chemical Studies. 2018;6(2):2114-2119. Available from: https:// www.chemijournal.com/archives/2018/vol6issue2/ PartAD/6-2-155-349.pdf

Norsworthy JK, Smith JP, Meister C. Tolerance of directseeded green onions to herbicides applied before or after crop emergence. Weed Technology. 2007;21(1):119-123. Available from: https://doi.org/10.1614/WT-06-042.1

Oliveira MG, Dias RC, Melo CAD, Mendes KF, Silva PV, Silva DV, Reis MR. Tolerância da cebola implantada por semeadura direta ao flumioxazin aplicado em pós-emergência inicial. Revista Brasileira de Herbicidas. 2018;17(2):585-563. Available from:https://doi.org/10.7824/rbh.v17i2.585

Priya RS, Chinnusamy C, Arthanari PM, Hariharasudhan V. A review on weed management in onion under Indian tropical condition. Chemical Science Review and Letters. 2017;22(6):923-932. Available from: https: //chesci.com/wpc o n t e n t / u p l o a d s/ $2017 / 06 /$ 
V6i22_41_CSo52048042_Sathya_923-932.pdf

Silva IPF, Junior JFS, Putti FF, Latorre DO, Schimidt AP, Ludwig R. Herbicidas 61 inibidores do fotossistema II parte II / photosystem II inhibitor herbicides - part. Revista Brasileira de Engenharia de Biossistemas.2013;7(1)12-22. Available from:https://doi.org/10.18011/bioeng2013v7n1p1 $-11$

Silva PV, Monquero PA. Influência da palha no controle químico de plantas daninhas no sistema de cana crua. Revista Brasileira de Herbicidas. 2013;12(1): 94-103. Available from: https://doi.org/10.7824//rbh.v12i1.235

Souza JI, Maciel CDG, Jadoski SO, Silva AAP, Matias JP. Resposta a aplicação sequencial tardia de herbicidas na cultura da cebola transplantada em diferentes arranjos de plantas. Brazilian Jounal of Applied technology for Agricultural Science. 2015;8(3)25-33. Available from: https://doi.org/10.5935/PAeT.V8.N2.03

Souza JI, Silva AAP, Chagas RR, Oliveira Neto AM, Maciel CDG, Resende JTV, Ono EO. Weed Interference Periods and Transplanting Densities of Onion Crop in the Brazilian Region of Guarapuava. Planta Daninha.2016;34(2)299-308. Available from: https://doi.org/10.1590/So10083582016340200011 